\title{
sciendo
}

\section{ANALYSIS OF GENETIC PARAMETERS OF CARCASS TRAITS AND DAILY GAIN OF NATIVE BREED PIGS RAISED IN POLAND*}

\author{
Magdalena Szyndler-Nędza' ${ }^{1}$, Robert Eckert ${ }^{1 \bullet}$, Mirosław Tyra ${ }^{1}$, Grzegorz Żak ${ }^{1}$, Karolina Szulc², \\ Tadeusz Blicharski ${ }^{3}$
}

\author{
'Department of Pig Breeding, National Research Institute of Animal Production, \\ 32-083 Balice n. Kraków, Poland \\ ${ }^{2}$ Department of Pig Breeding and Production, Poznań University of Life Sciences, Słoneczna 1, \\ 62-002 Suchy Las, Poland \\ ${ }^{3}$ Institute of Genetics and Animal Breeding, Polish Academy of Sciences in Jastrzębiec, Postępu 36 a, \\ 05-552 Magdalenka, Poland \\ •Corresponding author: robert.eckert@izoo.krakow.pl
}

\begin{abstract}
The aim of the study was to determine genetic parameters of live performance traits in pigs of three native breeds maintained in Poland. As part of the conservation programmes, the Pulawska (Pul), Zlotnicka White (ZW) and Zlotnicka Spotted (ZS) breeds are monitored for productivity based on performance test results of these breeds. The study included 6042 gilts and 2406 boars of the Pulawska breed, 866 Zlotnicka White gilts, and 903 Zlotnicka Spotted gilts. The genetic parameters were estimated separately for each breed, and also separately for sexes in the case of the Pulawska breed. The components (co)variance and genetic parameters were estimated using the REML method for the animal model taking into account different combination of fixed and random effects. Convergence of the iterative process was achieved by the selection of AIREML algorithm. The coefficients of genetic and phenotypic correlations between measurements of slaughter traits and daily gain were low for all breed groups. In turn, the relationships between backfat thickness measurements and carcass meat percentage were estimated as high. Only the correlations of slaughter traits with loin eye height were not uniform for the analysed breed groups. The coefficients of heritability $\left(h^{2}\right)$ were high and intermediate for all breeds and sexes. The highest heritability coefficients were obtained for daily gain ( 0.58 in $\mathrm{ZW}$ to 0.80 in Pul gilts), followed by backfat thickness (0.37 in Pul gilts to 0.64 in $\mathrm{ZW})$ and carcass meat percentage $(0.40$ in $\mathrm{ZS}$ to 0.56 in $\mathrm{ZW}$ ). The lowest coefficients were obtained for loin eye height ( 0.24 in Pul boars to 0.40 in $\mathrm{ZW}$ ). The estimated genetic parameters could be used to verify selection indices of the breeds included in the genetic resources conservation programmes.
\end{abstract}

Key words: pigs, native breeds, performance test, heritability, correlation coefficients

*The work was financed as part of the Biostrateg project (no. 297267) financed by the National Centre for Research and Development. 
In Poland, there are three breeds of native pigs: the Puławska, Złotnicka White and Złotnicka Spotted. The number of these animals is very small. In 2017, 1450 Puławska sows, 1022 Złotnicka White sows and 577 Złotnicka Spotted sows were used for reproduction (Szyndler-Nędza et al., 2018). Native breeds of pigs are genetically different from high-production breeds (Gurgul et al., 2018). They are less attractive for pig producers and breeders because of the poorer meatiness of the fattening pigs compared to the meatiness of high-lean fatteners. For this reason, the development of these populations is difficult and there is a real threat that they may become extinct. Animals of these breeds are characterised by traits that are valuable from an economic and breeding perspective. These include resistance to disease and stress and good maternal and prolificacy traits (Babicz et al., 2016). In addition, the meat and pork fat obtained from them have a unique taste and quality (Florowski et al., 2006; Szulc et al., 2012; Bogucka et al., 2016). For these reasons, Puławska, Złotnicka White and Złotnicka Spotted pigs have been included in the genetic resources conservation programme. These conservation programmes, developed by organisations supervising the breeding of Puławska (Polish Pig Breeders and Producers Association - "POLSUS"), Złotnicka White and Złotnicka Spotted pigs (Poznań University of Life Sciences), place particular emphasis on maintaining the characteristics of these breeds unchanged. In particular, the meat content of the carcass and the backfat thickness should not change. As part of the conservation programmes, these characteristics are monitored by analysing the performance test results of breeding animals as the basic information about their carcass traits and growth rate (Buczyński et al., 2015 a, b; Walkiewicz et al., 2017).

The applied performance testing method is one of the principal tools in selective breeding of highly productive breeds. The selection indices used in this method were elaborated based on genetic parameters estimated for these breeds for the purpose of monitoring changes in different populations of high-producing pigs (Szyndler-Nędza et al., 2010). Genetic parameters are also used to determine changes in the genetic value of production traits (Sullivan, 2007) or to perform economic analyses of breeding directions (Cassady and Robison, 2005). They also find application in determining breeding requirements which account for a number of new traits associated with the behaviour of pigs, among others (Rohrer et al., 2013). The efforts to make such an extensive use of genetic parameters have motivated us to analyse their values also in the native breeds of pigs, which are genetically and phenotypically distinct from high-producing breeds.

Because the work on the native breeds is not aimed to improve fattening and meat performance, no genetic parameters of these traits are available for local breeds in the international literature. In Poland, such research was conducted by Szyndler-Nędza et al. (2010) using the performance test results of the Puławska breed.

The objective of the study was to determine the genetic parameters of three native breeds of pigs raised in Poland. 


\section{Material and methods}

The study used the performance test results of Złotnicka White and Puławska pigs from 2010-2017 and of Złotnicka Spotted pigs from 2006-2017. The animals were performance tested in keeping with the methods adopted by relevant herdbook organisations. In accordance with performance testing methodology, the animals were tested at the age of 150-210 days (Puł) or 150-240 days (ZW, ZS). A Piglog 105 ultrasonic device was used to measure backfat thickness at P2 (on the back behind the last rib, $3 \mathrm{~cm}$ off the dorsal midline) and P4 (on the flank behind the last rib, $8 \mathrm{~cm}$ off the dorsal midline) and loin eye height at P4 (P4M). The following parameters were determined with regard to age and body weight of the animals tested:

- for ZW and ZS, daily gain standardised to 180 days of age, and lean meat percentage in accordance with the methods for performance testing of breeding gilts (Eckert and Szyndler-Nędza, 2004).

- for Pul, daily gain standardised to 180 days of age, and lean meat percentage standardised to $110 \mathrm{~kg}$ body weight and 180 days of age in accordance with the methods for performance testing of breeding boars and gilts (Eckert and SzyndlerNędza, 2017).

To estimate the genetic parameters, databases were searched to select animals from pig farms in which at least 5 offspring of one sex, sired by each Złotnicka White and Złotnicka Spotted boar, and at least 10 offspring of one sex sired by a Puławska boar, were tested. Due to the small number of performance tested boars of the Złotnicka breeds, the genetic parameters in these two breeds were only estimated for the gilts. In the case of the Puławska breed, the calculations were made for both the boars and the gilts.

After verification, the databases included performance test data for 2616 Puławska boars and 8222 Złotnicka White, Złotnicka Spotted and Puławska gilts. The number of herds and the number of sires and dams of the tested offspring - which served as a basis for further calculations - are presented according to breed in Table 1. The animal pedigrees were complete and included four generations. The coefficient of inbreeding was around $4 \%$ for all the breeds. The annual inbreeding increment averaged $0.3 \%$ for the Puławska breed, $0.6 \%$ for the Złotnicka Spotted breed and $0.7 \%$ for the Złotnicka White breed (Szyndler-Nędza et al., 2018).

Table 1. Number of breeding herds, sires and dams, and their offspring in each breed

\begin{tabular}{lcc|c|c}
\hline \multicolumn{1}{c}{ Breed } & Breeding herds & Sires & Dams & Offspring \\
\hline Złotnicka White gilts & 21 & 40 & 341 & 866 \\
Złotnicka Spotted gilts & 32 & 47 & 276 & 903 \\
Puławska gilts & 46 & 134 & 1036 & 6453 \\
Puławska boars & 31 & 84 & 577 & 2616 \\
\hline
\end{tabular}

The genetic parameters were calculated for traits of the pigs: two measurements of backfat thickness (at the P2 and P4 sites) and loin eye height (at P4M), carcass 
meat percentage and daily weight gain. The calculations were performed separately for each breed, and in the case of the Puławska breed, separately for both sexes. The components (co)variance and genetic parameters were estimated using the REML method for the animal model taking into account different combination of fixed and random effects. Convergence of the iterative process was achieved by the selection of AIREML algorithm. To estimate genetic parameters for their individual use in breeding programmes of each of these breeds, taking into account gender, the two models below were used; the components of the model were chosen based on the effects estimated from analysis of variance (ANOVA):

a) for the Złotnicka White and Złotnicka Spotted breeds

$$
Y_{i j k l}=m+a_{i}+s_{i j}+d_{i j k}+e_{i j k l}
$$

where:

$Y_{i j k l}-$ ijklth observation,

$m$ - the population mean,

$a_{i}$ - fixed effect of the herd,

$s_{i j}$ - random effect of jth sire,

$d_{i j k}$ - random effect of $\mathrm{kth}$ dam,

$e_{i j k l}-$ error.

b) for the Puławska breed (gilts and boars separately)

$$
Y_{i j k l m}=m+a_{i}+b_{j}+s_{i j k}+d_{i j k l}+e_{i j k l m}
$$

where:

$Y_{i j k l m}$-ijklmth observation,

$m$ - the population mean,

$a_{i}$ - fixed effect of the herd,

$b_{j}$ - fixed effect of the year,

$s_{i j k}$ - random effect of kth sire,

$d_{i j k l}$ - random effect of lth dam,

$e_{i j k l m}-$ error.

The genetic parameters were calculated using the DFREML package (Karin Meyer, v. 3.0) and statistical analyses were performed using the STATISTICA 12 package (StatSoft Polska).

\section{Results}

The means and standard deviations for the analysed performance test traits are presented in Table 2. The obtained results show that these breeds are phenotypically 
different. Złotnicka Spotted gilts had the thickest backfat at both measurement sites, and Puławska gilts by far the thinnest. P4M loin eye height was highest in Puławska gilts and lowest in Złotnicka Spotted gilts. Carcass meat percentage was highest in Puławska gilts, lowest in Złotnicka Spotted gilts, and intermediate in Złotnicka White gilts. Puławska boars were characterised by similar parameters of slaughter traits as Puławska gilts. By far the highest daily gain was observed in Puławska boars, and the lowest in Złotnicka Spotted gilts.

Table 2. Means and standard deviations for the analysed traits of Złotnicka White, Złotnicka Spotted and Puławska gilts, and Puławska boars

\begin{tabular}{l|c|c|c|c}
\hline \multicolumn{1}{c|}{ Trait } & \multirow{2}{*}{$\begin{array}{c}\text { Złotnicka White } \\
\text { gilts }\end{array}$} & $\begin{array}{c}\text { Złotnicka Spotted } \\
\text { gilts }\end{array}$ & \multicolumn{2}{|c}{ Puławska } \\
\cline { 4 - 5 } & $18.50 \pm 4.81$ & $20.80 \pm 5.35$ & $13.59 \pm 2.89$ & $14.57 \pm 3.66$ \\
\hline P2 backfat thickness (mm) & $17.64 \pm 4.68$ & $20.03 \pm 5.07$ & $13.05 \pm 2.81$ & $14.17 \pm 3.57$ \\
P4 backfat thickness (mm) & $45.22 \pm 5.91$ & $41.58 \pm 5.61$ & $51.46 \pm 5.65$ & $50.86 \pm 5.81$ \\
P4M loin eye height (mm) & $50.32 \pm 3.99$ & $47.47 \pm 4.26$ & $54.81 \pm 3.44$ & $53.47 \pm 3.95$ \\
Carcass meat percentage (\%) & $501 \pm 67$ & $428 \pm 64$ & $580 \pm 71$ & $602 \pm 79$ \\
Daily gain (g/day) & & & & boars \\
\hline
\end{tabular}

The coefficients of heritability $\left(\mathrm{h}^{2}\right)$ estimated for each breed were high for backfat thickness and daily gain (Table 3 ). The heritability values for daily gain, backfat thickness and meat percentage measurements in Złotnicka White and Złotnicka Spotted gilts range from 0.40 to 0.73 . Slightly lower were those for loin eye height $(<0.40)$. For Puławska gilts and boars, the heritability of slaughter and fattening traits was at a similar level as in the Złotnicka breeds. The highest heritability values were estimated for backfat thickness of boars and daily gains and meat percentage of gilts, and the lowest for loin eye height.

Table 3. Coefficients of heritability and estimation error for the analysed traits

\begin{tabular}{l|c|c|c|c}
\hline \multirow{2}{*}{\multicolumn{1}{c|}{ Trait }} & \multicolumn{3}{|c|}{ Gilts } & \multirow{2}{*}{ Puławska boars } \\
\cline { 2 - 3 } & $\begin{array}{c}\text { Złotnicka } \\
\text { White }\end{array}$ & $\begin{array}{c}\text { Złotnicka } \\
\text { Spotted }\end{array}$ & Puławska & \\
\hline P2 backfat thickness (mm) & $0.62 \pm 0.20$ & $0.51 \pm 0.13$ & $0.37 \pm 0.04$ & $0.56 \pm 0.09$ \\
P4 backfat thickness (mm) & $0.64 \pm 0.17$ & $0.41 \pm 0.29$ & $0.41 \pm 0.04$ & $0.57 \pm 0.08$ \\
P4M loin eye height (mm) & $0.40 \pm 0.09$ & $0.34 \pm 0.10$ & $0.25 \pm 0.03$ & $0.24 \pm 0.06$ \\
Carcass meat percentage (\%) & $0.56 \pm 0.24$ & $0.40 \pm 0.19$ & $0.52 \pm 0.04$ & $0.46 \pm 0.08$ \\
Daily gain (g/day) & $0.58 \pm 0.09$ & $0.73 \pm 0.10$ & $0.80 \pm 0.04$ & $0.73 \pm 0.06$ \\
\hline
\end{tabular}

The coefficients of phenotypic correlations $\left(r_{p}\right)$ between the different traits are shown according to the breed in Table 4 . The relationships between backfat thickness and meat percentage measurements were high and similar for gilts of the Złotnicka breeds (about -0.9). In the Puławska breed, these correlations were slightly lower: -0.71 for gilts and -0.78 for boars. Loin eye height showed by far lower correlations in 
all the breeds with backfat thickness and daily gain ( -0.12 to 0.21$)$. The relationships between loin eye height and carcass meat percentage in the Złotnicka and Puławska breeds showed different values; they were less than 0.2 in the Złotnicka breeds and exceeded 0.5 in the Puławska breed. Distinctly lowest correlations $(-0.02)$ were estimated between daily gain and P2 and P4 backfat thickness in Puławska gilts.

Table 4. Phenotypic correlations between the analysed traits of the three pig breeds

\begin{tabular}{l|c|c|c|c}
\hline \multirow{2}{*}{ Trait $\times$ trait } & \multicolumn{3}{|c|}{ Gilts } & \multirow{2}{*}{ Puławska boars } \\
\cline { 2 - 4 } & $\begin{array}{c}\text { Złotnicka } \\
\text { White }\end{array}$ & $\begin{array}{c}\text { Złotnicka } \\
\text { Spotted }\end{array}$ & Puławska & \\
\hline P2 $\times$ P4 & 0.87 & 0.86 & 0.69 & 0.75 \\
P2 $\times$ P4M & 0.15 & 0.21 & -0.12 & -0.12 \\
P2 $\times$ Percent* & -0.91 & -0.91 & -0.71 & -0.78 \\
P2 $\times$ Daily gain & 0.39 & 0.33 & -0.02 & -0.13 \\
P4 $\times$ P4M & 0.18 & 0.21 & -0.13 & -0.12 \\
P4 $\times$ Percent* & -0.90 & -0.92 & -0.71 & -0.77 \\
P4 $\times$ Daily gain & 0.36 & 0.29 & -0.02 & -0.12 \\
P4M $\times$ Percent* & 0.19 & 0.10 & 0.59 & 0.55 \\
P4M $\times$ Daily gain & 0.12 & 0.12 & 0.14 & 0.18 \\
Percent* $\times$ Daily gain & -0.35 & -0.29 & -0.19 & -0.07 \\
\hline
\end{tabular}

*Percent $=$ Carcass meat percentage.

Table 5. Genetic correlations between the analysed traits of the three pig breeds

\begin{tabular}{l|c|c|c|c}
\hline \multirow{2}{*}{ Trait $\times$ trait } & \multicolumn{3}{c}{ Gilts } & \multirow{2}{*}{ Puławska boars } \\
\cline { 2 - 3 } & $\begin{array}{c}\text { Złotnicka } \\
\text { White }\end{array}$ & $\begin{array}{c}\text { Złotnicka } \\
\text { Spotted }\end{array}$ & Puławska & 0.96 \\
\hline P2 $\times$ P4 & 0.96 & 0.94 & 0.96 & 0.19 \\
P2 × P4M & 0.38 & 0.43 & -0.04 & -0.86 \\
P2 × Percent* & -0.93 & -0.93 & -0.71 & -0.29 \\
P2 × Daily gain & 0.45 & 0.24 & 0.07 & 0.14 \\
P4 × P4M & 0.36 & 0.37 & -0.05 & -0.91 \\
P4 × Percent* & -0.94 & -0.95 & -0.75 & -0.10 \\
P4 × Daily gain & 0.39 & 0.10 & 0.09 & 0.10 \\
P4M $\times$ Percent* & -0.06 & -0.10 & 0.40 & 0.15 \\
P4M $\times$ Daily gain & 0.18 & 0.20 & 0.05 & 0.03 \\
Percent* $\times$ Daily gain & -0.39 & -0.12 & -0.45 & \\
\hline
\end{tabular}

*Percent $=$ Carcass meat percentage.

Table 5 shows the genetic correlations $\left(\mathrm{r}_{\mathrm{G}}\right)$ between the analysed traits according to breed. The coefficients of genetic correlation for slaughter and fattening traits followed a similar pattern to the phenotypic correlations. The highest correlations 
were estimated between measurements of backfat thickness, and also between these measurements and carcass meat percentage (above 0.9 in the Złotnicka breeds and above 0.7 in the Puławska breed). By far the lowest genetic correlations were calculated between loin eye height and backfat thickness; they ranged from 0.36 to 0.43 for the Złotnicka White and Złotnicka Spotted breeds, and from -0.04 to 0.19 for the Puławska gilts and Puławska boars. The relationships between P4M measurement and carcass meat percentage were lowest and ranged from -0.06 to -0.10 for the Złotnicka gilts and Puławska boars (0.10); this correlation was fairly high (0.40) only for the Puławska gilts. As regards the relationships between daily gain and P2, P4 and P4M measurements, the coefficients of genetic correlation were at an intermediate level for the Złotnicka gilts $(0.10-0.45)$ and Puławska boars $(-0.29-0.15)$, and below 0.10 for the Puławska gilts.

\section{Discussion}

The mean performance test results of the Złotnicka White, Złotnicka Spotted and Puławska gilts and Puławska boars were at the intermediate level of the performance test results for each of these breeds as reported in 2017 by Eckert and SzyndlerNędza (2017) and Eckert et al. (2017). This means that the analysed data reflected the current productive value of these breeds in terms of the performance test.

When choosing different models for estimation of heritability in such small populations, we attempted to minimise the estimation error for this parameter. While for the larger population of Puławska gilts and boars low estimation errors of the heritability coefficient were obtained for all the traits, the estimation error for the much smaller populations of Złotnicka White and Złotnicka Spotted gilts were much higher for some of the traits.

In general, high and intermediate coefficients of heritability were estimated for all the breeds and sexes, which is expected to increase breeding progress for particular traits. The highest $h^{2}$ values were obtained for daily gain, followed by backfat thickness and carcass meat percentage. The lowest $\mathrm{h}^{2}$ values were noted for the measurement of loin eye height. The obtained results correspond with the results of studies with pigs of different high-producing breeds. Szyndler-Nędza et al. (2010) and Choi et al. (2013) also showed the highest heritability coefficients for daily gains and the lowest for loin eye measurements. Different results for daily gain were obtained for Large White, Landrace and Duroc breeds by Skorupski et al. (1996), who reported a low value of this parameter $\left(h^{2}=0.2\right)$. As regards backfat thickness measurements, our results are similar to those obtained for Norwegian Landrace pigs by Holm et al. (2004), who reported similar coefficients of heritability (0.44 to 0.46$)$ as in our study. These results correspond with the values reported by commercial companies, where this parameter ranged from 0.49 to 0.50 (Sullivan, 2007). Slightly lower but still intermediate heritability values for backfat thickness measurements $(0.32-0.41)$ were obtained by Choi et al. (2013). In turn, the coefficients of heritability for carcass meat percentage, estimated in our study for all the breed groups, are consistent with 
the findings of Rothschild and Ruvinski (1998) and Cassady and Robison (2005), who estimated them as 0.45 to 0.48 .

Different results were obtained for heritability of performance traits estimated in the small conservation breed of Korean Native Pigs. Kim et al. (2007) obtained heritability values for backfat thickness (0.29) and daily gain (0.26).

Analysis of the correlations between the analysed traits showed a similar distribution of phenotypic and genetic correlations. In addition, no large differences were observed between the breed groups. Only in the case of Puławska gilts were the phenotypic and genetic correlations of backfat thickness with meat percentage slightly lower, and those with daily gain were much lower. A similar situation occurred for the relationship of loin eye height with daily gain and meat percentage, where the correlations for Puławska gilts differed from the same parameters estimated for the other groups. In general, the relationships between slaughter traits and daily gain for the analysed breed groups were very low. This is supported by the findings of Cassady and Robison (2005), where the correlation between backfat thickness and daily gain was 0.12 . Also Choi et al. (2013) determined the relationships between growth rate and backfat thickness below 0.10. Only in the study by Skorupski et al. (1996) did the correlations between daily gain and backfat thickness, estimated for different breeds range from 0.30 to 0.40 . This is consistent with our results obtained for the Złotnicka White breed.

The results obtained in the Złotnicka White and Złotnicka Spotted gilts for the relationships between ultrasound measurements (P2, P4, P4M) agree with Choi et al. (2013), where the genetic correlations between backfat thickness and loin eye area ranged from -0.33 to -0.38 . A similar value $(0.4)$ was obtained by Cassady and Robison (2005). The correlations obtained in our study for the Puławska gilts and boars were considerably lower, which is not supported by the available literature.

\section{Conclusions}

In summing up the results, it is stated that high phenotypic and genetic correlations were estimated for the analysed breeds between ultrasound measurements of backfat thickness (P2 and $\mathrm{P} 4)$ and carcass meat percentage ( $\mathrm{r}_{\mathrm{P}}$ from -0.71 to -0.92 ; $\mathrm{r}_{\mathrm{G}}$ from -0.71 to -0.95$)$, which shows that it is appropriate to use these measurements for live evaluation of meat percentage in these breeds. In the case of loin eye height (P4M), the results were not as conclusive. The highest coefficients of phenotypic and genetic correlations between this trait and carcass meat percentage were estimated only for the Puławska breed (ca. $\mathrm{r}_{\mathrm{P}}=0.60$ for Puławska gilts and boars, and $\mathrm{r}_{\mathrm{G}}=0.40$ for Puławska gilts only); in the other groups these correlations were at a low level. The coefficients of heritability for the Puławska and both Złotnicka breeds were estimated as high for daily gain and as intermediate for backfat thickness and carcass meat percentage. This means that rapid breeding progress can be obtained for these traits in these breeds. The estimated genetic parameters could be used to verify selection indices while accounting for the objectives of the genetic resources conservation programmes for each of these breeds. 


\section{References}

Babicz M., Szyndler-Nędza M., Skrzypczak E., Kasprzyk A. (2016). Reproductive performance of native Pulawska and high productivity Polish Landrace sows in the context of stress during the period of early pregnancy. Reprod. Dom. Anim., 51: 91-97.

B o g u c k a J., K a p e la ńs ki W. (2016). Microstructure of longissimus lumborum muscle and meat quality of native Polish pig breeds: Złotnicka spotted and Puławska. Ann. Anim. Sci., 16: 1199-210.

Buczyński J., Szulc K., Luciński P., Szyndler-Nędza M. (2015 a). Genetic resources conservation programme for Złotnicka White pigs (in Polish). http://www.bioroznorodnosc.izoo. krakow.pl

Buczyński J., Szulc K., Luciński P., Szyndler-Nędza M. (2015 b). Genetic resources conservation programme for Złotnicka Spotted pigs (in Polish). http://www.bioroznorodnosc.izoo. krakow.pl

Ca s s a d y J., R o b i s o n O.W. (2005). Genetic parameters and their use in swine breeding. Pork industry handbook. Purdue Extension, 06-01-05: 1-4.

Cho i J.G., Cho C., Cho i I.S., L e e S.S., Choi T.J., Cho K.H., P ark B.H., Choy Y.H. (2013). Genetic parameter estimation in seedstock swine population for growth performances. Asian-Australas. J. Anim. Sci., 26: 470-475.

E c k e r t R., S z y n d l e r - N ę d z a M. (2004). Results of performance tested boars (in Polish). Report on pig breeding in Poland. Kraków, XXII: 30-53.

E c kert R., S z y n d l e r - N ę d z a M. (2017). Results of performance tested boars (in Polish). Report on pig breeding in Poland. Kraków, XXXV: 19-33.

E c k e r t R., Ż a k G., B e r e t a A. (2017). Results of performance tested gilts (in Polish). Report on pig breeding in Poland. Kraków, XXXV: 34-48.

Florowski T., Pisula A., Adamczak L., Buczyński J.T., Orzechowska B. (2006). Technological parameters of meat in pigs of two Polish local breeds - Zlotnicka Spotted and Pulawska. Anim. Sci. Pap. Rep., 24: 217-224.

Gurgul A., Jasielczuk I., Ropka-Molik K., Semik-Gurgul E., Pawlina-Tyszko K., Szmatoła T., Szyndler-Nędza M., Bugno-Poniewierska M., Blicharski T., Szulc K., Skrzypczak E., Krupiński J. (2018). A genome-wide detection of selection signatures in conserved and commercial pig breeds maintained in Poland. BMC Genetics, 19: 95. https://doi.org/10.1186/s12863-018-0681-0

Ho $1 \mathrm{~m}$ B., B a k ken M., K 1 e met s d a 1 G., Vangen O. (2004). Genetic correlations between reproduction traits in swine. J. Anim. Sci., 82: 3458-3464.

K i m M.J., Cho K.H., J e on G.J., K i m Y.H., Park J.C., Jung H.J., Kim I.C., K wo n O.S. (2007). Study on estimation of genetic parameters for the meat production traits and the standard growth curve in the inbred line of Korean Native pigs. J. Embryo Transf., 22: 143-147.

Rohrer G.A., Brown-Brand 1 T., Re mpel L.A., S chne ider J.F., Holl J. (2013). Genetic analysis of behavior traits in swine production. Livestock Sci., 157: 28-37.

R oth s child M.F., R uvin s ky A. (1998). The genetics of the pig. CAB International, Wallingford, Oxon, UK: 313-343.

S k or u p s k i M.T., Garri c k D.J., B l a i r H.T. (1996). Estimates of genetic parameters for production and reproduction traits in three breeds of pigs. New Zeal. J. Agr. Res., 39: 387-395.

Sulliv a n B.P. (2007). Genetic sources of variability in pig production. Advances in pork production University of Alberta, 18: 131-137.

Szulc K., Skrzypczak E., Buczyński J.T., Stan isławski D., Jankowska-Mąko$\mathrm{s}$ a A., Kne cht D. (2012). Evaluation of fattening and slaughter performance and determination of meat quality in Złotnicka Spotted pigs and their crosses with the Duroc breed. Czech. J. Anim. Sci., 57: 95-107.

Szyndler-Nędza M., Tyra M., Róży cki M. (2010). Coefficient of heritability for fattening and slaughter traits included in modified performance testing method. Ann. Anim. Sci., 10: $117-125$.

Szyndler-Nędza M., Luc iński P., Skrzypczak E., Szulc K., B aj da Z. (2018). Native breeds of pigs - state of breeding and results of evaluation (in Polish). IZ PIB, Kraków, 13: 3-40. 
Walkiewicz A., Kasprzyk A., Babicz M., Kondracki S., Blicharski T., Bajda Z., Róży cki M., S zy nd le r-Nędza M., J a s z c zy ńsk a M. (2017). Genetic resources conservation programme for Puławska pigs (in Polish). http://www.bioroznorodnosc.izoo.krakow.pl

Received: 23 VII 2018

Accepted: 20 II 2019 